See discussions, stats, and author profiles for this publication at: https://www.researchgate.net/publication/311956623

\title{
Putting the Present in the History of Autism
}

Article in Studies in History and Philosophy of Science Part C Studies in History and Philosophy of Biological and Biomedical Sciences · December 2016

DOI: 10.1016/j.shpsc.2016.11.002

CITATIONS

0

1 author:

Sam Fellowes

Lancaster University

5 PUBLICATIONS 5 CITATIONS

SEE PROFILE
READS

21

All content following this page was uploaded by Sam Fellowes on 06 January 2017. 


\section{Uncorrected Proof}

Final version available from the Studies in the History and Philosophy of the Biological and

Biomedical Sciences, currently not assigned to an issue but is available here

http://www.sciencedirect.com/science/article/pii/S1369848616300954 Only reference the published article and not this uncorrected proof.

\section{Putting the present into the history of autism}

Sam Fellowes

Department of Politics, Philosophy and Religion, County South, Lancaster University, Lancaster LA1 4YL UK, m.fellowes1@lancaster.ac.uk

In a Different Key: The Story of Autism

John Donovan and Caren Zucker, Broadway Books: New York, NY, 2016, pp. 608, Price $£ 13.67$

paperback, ISBN:9780307985705

Neurotribes: The Legacy of Autism and the Future of Neurodiversity

Steve Silberman, Atlantic Books: London, 2015, pp. 608, Price $£ 6.99$ paperback, ISBN:9781760293284

\section{Introduction}

Autism has gone from being largely unknown a few decades ago to become influential in modern United States and British culture. Both Steve Silberman's Neurotribes (2015) and John Donvan \& Karen Zucker's In A Different Key (2016) chart the history of autism, from early conceptions to the present-day's integration of autism within modern culture. Both consider this integration as largely a positive force for autistic people, especially in comparison to approaches of earlier decades. The books cover some similar content, both describing initial 1940s notions, development of psychoanalysis and mother blaming, pharamacological treatments, behaviourist treatments, parent movements, educational tools, 1980s notions of an autistic spectrum, scares over vaccinations and the neurodiversity movement.

Recent media reviews of these books have been generally positive and although I highlight the positive elements, my primary focus is on some of the significant problems in these books. Both books have made some historical errors but they seem more problematic in Silberman's case. Donvan \& Zucker largely stick to describing a series of events whereas Silberman weaves specific events into a wider narrative, one which treats the modern classification of autism as correct scientific fact. The only evidence present in Neurotribes for this approach is implicit in Silberman's history: the classification of autism employed historically used to be deeply flawed so therefore our modern notion is good. I will highlight problematic historical assertions both books make but largely focus upon showing how those errors undermine Silberman's narrative. This critique gives more credibility to the alternative conceptions of autism he largely dismisses.

As an individual diagnosed as autistic I believe the degree to which I should allow modern notions of autism to influence my self-perception, my identity and any support I receive should partially depend upon the epistemic worth of the modern concept. The history of autism certainly has potential use here, a source of alternative conceptualizations and approaches to compare modern autism with. Silberman believes modern autism compares well, a claim which could influence the perceptions 
of autistic individuals, scientists and our wider culture towards modern autism. Whilst I believe modern autism has some significant epistemic worth I also accept the possibility that some classifications from earlier decades could have even higher epistemic worth. They need balanced historical investigation rather than Silberman's unfair dismissal.

\section{Silberman's Narrative}

Silberman in Neurotribes asserts that "nearly eighty years after the discovery of the autistic continuum by Asperger's team at the Heilpädogogik Station, its full breadth was finally reflected" in the DSM [Diagnostic Statistical Manual], referring to changes to the criteria for autism brought about by the 2013 DSM-5 (p.503). This statement encapsulates Silberman's narrative: that the autistic spectrum was discovered in the 1940s but then forgotten, and was only reintroduced in the mid-1980's and fully implemented with DSM-5 in 2013. Silberman primarily blames the Austrian-born, Baltimore-based, child psychiatry pioneer Leo Kanner for the decades-long delay in adopting the autistic spectrum, writing that "the adoption of the spectrum model of autism by the psychiatric establishment in the 1980s represented a decisive defeat for the father of the diagnosis" (pp.43-44).

Leo Kanner was a major figure in American child psychiatry from the 1930s to the 1970s, managing the first American child psychiatric clinic and publishing the first English language textbook on child psychiatry. In 1943 he published a paper describing a condition that he believed differed "markedly and uniquely from anything reported so far" in children he considered to exhibit "an extreme autistic aloneness, that, whenever possible, disregards, ignores, shuts out anything that comes to the child from the outside" (Kanner, 1943, p. 217; p.242, emphasis in original). While it is not completely unrelated, historical scholarship generally agrees that Kanner's autism describes a much more specific symptom pattern than modern autism (Evans, 2013, p.23; Eyal et al, 2010, p.130; Jacobsen, 2010, p.438; Verheoff, 2013, p.452). Silberman writes that "[f]or decades, Kanner maintained that his syndrome was monolithic by definition, limited to childhood, and vanishingly rare" (p.44). Silberman claims this notion of autism "prevailed for half a century, virtually unquestioned by clinicians" but by the 1987 DSM-III-R "autism had been transformed into something that Kanner would have barely recognised" (p.151;424).

Donvan \& Zucker also contrast Kanner's autism with the 1980s spectrum, citing the leading autism researcher Lorna Wing who thought that

"the condition had been too tightly inscribed. It was time to move beyond seeing autistic traits as meaningful only when they were locked together into a supposedly tight syndrome, as Kanner had done" (p.311).

Unlike Silberman, they are less specific about what Kanner's autism entailed and do not blame him for the delayed adoption of a spectrum.

Silberman contrasts Kanner's autism with the Austrian pediatrician Hans Asperger's discovery of the autistic spectrum in the 1940s (see Asperger (1944)). Although Asperger's work was largely unknown to the English speaking world until the 1980s, there is an ongoing debate over whether Kanner knew of Asperger's work and plagiarised it (see Chown, 2012, p.2264; Fellowes, 2015, p.2275; Lyons \& Fitzgerald, 2007, p.2022; Olmsted \& Blaxhill, 2015, p.340). Silberman's evidence is the strongest yet provided that Kanner possibly knew of Asperger's work. Among the fellow Jewish refugees Kanner helped emigrate from 1930's Europe was George Frankl, Asperger's chief diagnostician, whom Kanner would later work with. However, Silberman suggests Kanner disregarded rather than plagiarised Asperger's notions. Frankl shared Asperger's notions of a spectrum that 
"stretched from children with profound intellectual disability to "astonishing" child prodigies. But [argues Silberman] his inclusive conception of autism was to be doomed to obscurity by the man [Kanner] who had saved his life from the gas chamber"

(pp.199-200).

Silberman's narrative sees the autistic spectrum as a fact that was discovered in the 1940s, forgotten about because Kanner's narrower definition was adopted, but then reimplemented by the 1980s autistic spectrum.

\section{Historical issues}

Although Silberman's claims that Kanner's autism was "monolithic by definition, limited to childhood, and vanishingly rare" (p.44) and was "virtually unquestioned by clinicians" (p.151), both his book and In a Different Key actually implicitly suggest it was largely unused.

"[Kanner] was sitting at the apex of a pyramid designed to filter all but the most profoundly disabled children of the most well-connected families in America out... The milder cases among the two hundred children seen by Asperger in Vienna would likely have never made it to the top of his pyramid" (pp.207-208; also Donvan \& Zucker, p.89).

If Kanner's autism was only rarely diagnosed then what happened to children with less rare, less monolithic and less severe symptoms? This question is not explicitly addressed and posing it makes Silberman's narrative difficult to follow.

First, autism was often diagnosed on criteria other than those established by Kanner, who in fact had noted that "in some quarters to [there is] a dilution of the concept of early infantile autism, and the diagnosis has been made much too prodigiously" (Kanner, 1958, p.110). Silberman notes that Kanner stated he "turned away nine out of ten children referred to his office as "autistic" by other clinicians without an autism diagnosis" (pp.238-239; also Donvan \& Zucker, p.279). Thus Kanner was one of the few child psychiatrists employing his narrow notion of autism but there were also alternative notions being employed. Neither Silberman nor Donvan \& Zucker outline these non-Kanner notions of autism, leaving it unclear if they were less rare, less monolithic or resembled a spectrum. These are possibilities given that Kanner felt "his whole concept was being watered down" (Donvan \& Zucker, p.279), leaving the lack of investigation into non-Kanner notions of autism a significant omission for Silberman's argument.

Second, despite his claim that spectra only became employed in the mid-1980s, Silberman describes a diagnosis employed between the 1930s to 1970s, childhood schizophrenia, as a spectrum:

"the childhood schizophrenia "spectrum" was much more inclusive than Kanner's conception of his syndrome, children who displayed many traits now considered classic signs of autism but showed no delay in acquiring language often ended up with that diagnosis" (p.226).

Silberman puts "spectrum" in scare quotes, making it unclear whether he thinks childhood schizophrenia was or was not a spectrum. He provides no explicit answer and his other claims also leave this issue obscure. For instance, he mentions the work Lauretta Bender who described

"a number of behaviours that are now considered classic signs of autism... her accounts of childhood schizophrenia were closer to Asperger's and Frankl's description of autistic 
psychopathy than Kanner's constricted view of his syndrome" (p.210). ${ }^{1}$

If childhood schizophrenia was a spectrum, however, then how was the 1980s autistic spectrum new and how could Kanner be blamed for its earlier non-adoption? Since childhood schizophrenia was diagnosed and written about much more than autism (Donvan \& Zucker p.365; Eyal et al, 2010, p.128; Silverman, 2012, pp.39-40), Silberman's lack of clarity over whether childhood schizophrenia was a spectrum is a significant omission.

Silberman further complicates his argument by describing how Kanner's views changed. Kanner initially considered autism separate from childhood schizophrenia but

"saw the writing on the wall early on. While continuing to insist that his syndrome was a condition sui generis, he quietly folded it into the schizophrenia section... [then] officially waved the white flag [in 1949]" (p.211).

Similarly, Donvan \& Zucker write that "Kanner began to waver in his convictions about the significance of his own findings. He even revised his textbook during this period [1948], moving infantile autism to the schizophrenia category" (p.89). This shift occurred before 1950 and before much had been published on autism (Silberman, p.210). Thus it is unclear how Kanner's initial 1943 stance could have prevented a spectrum arising for three decades. Alternatively, might Kanner's 1948 onwards approach have prevented a spectrum arising? According to Silberman,

Kanner attempted to negotiate a truce with [childhood schizophrenia] researchers... if they would let him have his rare, narrowly defined syndrome, he would yield the rest of Szurek's "spectrum" to the ever-expanding field of childhood schizophrenia" (p.212). ${ }^{2}$

This analysis suggests that, to whatever degree childhood schizophrenia was a spectrum, Kanner's autism was not part of it. Yet, by 1958 Kanner was of the opinion that

"[t]he various forms of childhood schizophrenia share with early infantile autism the loss of effective contact and autistic thinking... Communication and affective perceptions are not usually as deeply disturbed as in autistic children. In the broader schizophrenic group there may also be a wider variety of symptoms" (Kanner \& Lesser, 1958, p.728).

To the degree that spectrum entail similarities of symptoms but variations in severity then Kanner's position is closer to a spectrum than Silberman states, seeing autism as a more severe form of childhood schizophrenia which exhibits similar but less severe symptoms.

Silberman admits that Kanner eventually changed his mind about notions of a spectrum because "dramatic differences in the life courses of his patients finally led Kannerhim to question his belief that is syndrome was narrowly defined and monolithic" (p. 237). He dates Kanner's shift to the 1970s, citing a 1971 publication where Kanner claimed "It is well known in medicine that any illness may appear in different degrees of severity, all the way from the so-called forme fruste to the most fulminant manifestation' (Kanner, 1971, as quoted by Silberman, p.237). But a look at Kanner's writings suggests he had begun to move toward a spectrum position much earlier. For instance, already in the 1950s he had noted "differences in the intensity of autistic aloneness and fragmentation"

1 Lauretta Bender (1897-1987) was a New York based child psychiatrist and the leading childhood schizophrenia researcher.

2 Stanislaus Andrew Szurek was a San Francisco based Czech child psychiatrist who researched childhood schizophrenia. 
(Kanner \& Eisenberg, 1955, p.232) and “degree[s] of autistic isolation” (Kanner \& Lesser, 1958, p.726).

Silberman also criticises Kanner's autism for being restricted to children. Silberman's concern would have force if there were no suitable diagnosis for adults; if Kanner had not discussed autistic adults; or if Kanner objected to post-childhood autism diagnosis. Unfortunately, Silberman does not discuss what diagnoses were employed for adults, making it unclear what diagnoses were available for individuals whose symptoms only became noticed in adulthood. Furthermore, Kanner wrote a commentary for a 1951 article which described "one autistic child who has reached adulthood. The two decades before us ought to tell much about the destiny of those [autistic children] now observed and various treated" (Kanner in Darr \& Worden, 1951, p.570). Here Kanner recognised autistic children can exhibit autistic symptoms as adults whilst showing a wise caution about what autistic adults will be like. Significantly, the woman in that 1951 article was twenty-two years old at the time of Kanner's initial 1943 autism publication and yet he considered her autistic, which tells us that he considered diagnosing adults (who were undiagnosed as children) with autism as legitimate. Silberman is mistaken to claim Kanner thought autism was restricted children.

Silberman's evidence does not support Kanner's autism as monolithic and restricted to children whilst he is correct that Kanner's autism was extremely rare, his interpretation needs to be understood in the context of it being a subtype of the less rare childhood schizophrenia.

\section{Philosophical issues}

In proclaiming the "discovery" of an autistic spectrum (p.503), Silberman's narrative implicitly treats the autistic spectrum as a fact waiting to be discovered. This approach is potentially problematic. Is the autistic spectrum something which exists factually independent of our beliefs or is it a methodological convention adopted to classify individuals with some similarities of symptoms? Silberman does not explicitly address these issues but uncritically seems to take the former approach. Whilst not untenable, that approach is less popular among philosophers of psychiatry and therefore more controversial (see Cooper, 2007, p.46; Murphy 2006, p.316; Zachar 2014, p.154). Even if we accept the factual approach, Silberman offers no evidence that the facts entail the autistic spectrum rather than an alternative such as a multiple demarcated diagnosis. Donvan \& Zucker seem to implicitly alternate between each approach, sometimes closer to spectrum as fact and sometimes closer to spectrum as convention (compare for example Donvan \& Zucker, 2016, p. 426 with p.367). Some recent commentators have argued modern autism is flawed because of the highly diverse causal basis (Cushing, 2013, p.38; Timimi et al, 2011, p.7). Silberman mentions the highly diverse causal basis (p.14) and suggests autism is not a unified condition (p.510). Without addressing whether these issues supports a spectrum or an alternative Silberman and to a lesser degree, Donvan \& Zucker should have remained more noncommittal rather than present the autistic spectrum as fact.

Silberman also unfairly favours a particular notion of spectrum. One can simply employ a spectrum or one can include subtypes within a spectrum. Subtypes advantageously allow greater specificity of symptom descriptions but disadvantageously there is usually no obvious or unproblematic way of placing the boundaries of subtypes. Silberman actually engages in these debates but only when it comes to childhood schizophrenia, not mentioning the possibility of subtyping modern autism. He simultaneously criticises childhood schizophrenia as too broad (p.211) whilst criticizing an early subdivision of childhood schizophrenia as being "prefabricated pigeonholes" (p.187). Which is worse, being too broad or employing arbitrary subtypes? Silberman does not address this question but the man he primarily criticizes did. Kanner argued childhood schizophrenia was too broad (1953, p.528) and considered autism as one of three subtypes of childhood schizophrenia (Kanner, 1969, p.3). Silberman actually praises Kanner's 1943 paper as "a paragon of clinical clarity... he lifted the gestalt of the 
syndrome... made it visible as a diagnostic entity apart from the undifferentiated mass of "prepsychotic" children" (p.194). This accurate claim sits uneasily, however, with Silberman's regular complaint that Kanner's autism was too narrow. Plausibly, a narrow definition was a worthwhile tradeoff to provide the very nebulous childhood schizophrenia with a more precise subtype. At minimum, Kanner's approach was a legitimate option rather than uncontroversially mistaken. If this is true of childhood schizophrenia then it is largely true of modern autism also. Though less broad than childhood schizophrenia was, significant variations in clinical picture means subtyping modern autism cannot be dismissed. Without first providing arguments for a non-subtyped spectrum Silberman should be more open to non-subtyped DSM-5 autism being inferior to a subtype approach (such as Kanner's precise subtypes or DSM-IV's less precise subtypes).

Uncritically endorsing DSM-5 autistic spectrum as something to be discovered gives Silberman a standard to assess history - past child psychiatrists are praised for being closer to a non-subtyped spectrum and criticized for being further away. If a non-spectrum approach or a subtyped spectrum approach is superior to DSM-5 then Silberman's standards for assessing history is flawed. Kanner may thus not deserve Silberman's criticism.

\section{Treatment and neurodiversity}

The strongest feature of both Silberman's and Donvan \& Zucker's books is their coverage of the more recent history of autism research. Their histories of the period following the1960s are less problematic and make more novel contributions. Whereas earlier history of autism books by Nadesan (2005), Feinstein (2010), Eyal et al (2010) and Silverman (2012) cover development of educational technologies, parents movements, scares over vaccinations and neurodiversity, the books reviewed in this essay provide more detail on specific figures, their specific actions and their specific disputes with other historical figures. Silberman's and Donvan \& Zucker's books are to be recommended to historians dealing with such issues.

Silberman also makes another unsupported claim, based on his belief that the adoption of a spectrum substantially improved conditions for autistic individuals.

"By overturning his [Kanner's] conception of autism as a rare, inevitably devastating and homogeneous disorder, [Lorna Wing] made it possible for tens of thousands of children, teenagers, and adults to gain access to the educational placements and social services they deserved" (p.44).

Silberman links this lack of support with autism being too narrowly conceived before the 1980s. However, Silberman's history does not cover pre-1980s diagnosis for adults or pre-1980s services available for individuals only diagnosed as adults. Without addressing these issues Silberman cannot support claims that implementing the 1980s autistic spectrum lead to increased access to services. More fundamentally, there appears no obvious connection between diagnosis employed and support provided. Imagine that Kanner's 1943 paper actually listed DSM-5 diagnostic criteria and these were immediately given widespread employment whilst childhood schizophrenia was immediately abandoned. Are we to presume that the positive elements associated with a diagnosis today would also have been present throughout the 1950s, 1960s and 1970s? Alternatively, imagine if pre-1980s notions of childhood schizophrenia had been retained by post-1980 editions of the DSM whilst autism remained as Kanner's narrow notion. Does this mean that none of the positive elements of being diagnosed with modern autism would have become associated with a post 1980s childhood schizophrenia? Plausibly treatment and services are influenced by many more factors than the 
diagnosis employed, such as the disability rights movement and increasing community care. Silberman needs to offer stronger evidence to claim Kanner's notion of autism prevented many individuals receiving helpful support. Donvan \& Zucker make similar omissions, though only over who was diagnosed rather than support given. Without a

"big, wide, deep and blurry spectrum... it seems unlikely that the notion of autism Leo Kanner coined in 1943 could legitimately be stretched to include large numbers of people as intelligent, talented, and independent" (p.519).

Aupporting this claim requires evidence thatg childhood schizophrenia or adult diagnosis could not have also diagnosed successful higher functioning individuals but neither book explores these issues.

Whilst Silberman and Donvan \& Zucker are correct in claiming that autism as a potentially positive thing is a relatively new idea, the notion was not completely absent in Kanner's later thoughts. In 1973 he wrote that some autistic individuals

"received-and enjoyed-the recognition earned by the detailed knowledge they had stored up years of obsessive rumination of specific topics... Rewards came to them also from their employers who... remarked on their meticulousness and trustworthiness. Life among people thus lost its former menacing aspects. Nobody has shoved them forcibly through a gate which others had tried to unlock for them; it was they who, at first timidly and experimentally, then more resolutely, paved their way to it and walked through" (Kanner, 1973, p.221 emphasis original)

Thus, Kanner recognised autism need not be truly disabling or without benefits and that autistic individuals could play a role in improving their own lives.

\section{Conclusion}

Since its publication Neurotribes has become enormously influential within online, written and media discussions in various forums about what autism is and how society should approach it, more so than any other historically focused text on the subject. This makes Neurotribes important to me since, for an autistic individual such as myself, modern approaches to autism have the potential to influence my selfperception, my identity and any support I receive. Despite my heavy criticism of Neurotribes I largely share its positive message. I immensely benefited immensely by being diagnosed and I believe this is partly because modern autism has significant scientific worth, getting something right about reality. Despite this, Neurotribes has significant potential for harm. I believe modern autism is making positive contribution but a rich variety of substantive sub-types of autism might get something even more right about reality and thus make an even greater contribution to the self-perception, identity and support provided to those currently diagnosed with autism.

Silberman's narrative is potentially harmful because it so heavily favours modern autism with its non-subtyped spectrum over alternative pre-1980s type approaches without acknowledging the legitimacy of alternatives to non-subtyped spectrums. Additionally, the evidence Silberman employs in favour of non-subtyped spectrums is flawed. Those writing history always risk putting the present into historical writing and Silberman falls into this trap. The main evidence provided to support modern autism is criticism of pre-1980s diagnosis. However, criticism of pre-1980s approaches is partially based in assuming modern autism is correct. This circular argument (further compounded by some historical errors) illegitimately supports modern autism. Undeniably, the many positive benefits associated with being diagnosed as autistic today are preferable to motherblaming psychoanalysis, 
experimental drugs and asylum places associated with the pre-1980s. However, these issues are only distantly connected to which diagnoses are employed. They could have occurred alongside many different approaches to diagnosis yet Silberman entirely favours a non-subtyped spectrum. All this is especially concerning because Silbermans asks relevant critical questions of childhood schizophrenia, considering it too broad whilst considering its subtypes as arbitrary, yet does not ask similar questions of modern autism. Seeing how non-spectrum and subtyped spectrums worked historically is an important source of information provided they are interpreted from a standpoint other than assuming modern autism is unambigiously correct. Whilst modern autism is not uncontroversially substantially flawed, non-spectrum approaches and subtyped spectrums deserve investigation.

Donvan \& Zucker's book is less problematic because the limited scope of their claims also limits the consequences of their historical errors. Lacking the large narrative of Neurotribes and its striking comparison between modern approaches and earlier approaches, In a Different Key largely manages to avoid transmitting any harmful messages while containing a significant amount of easily readable historical material. Academic historians aware of Silberman's problematic narrative may find both books' novel content worth reading but for non-specialists I would recommend Donvan \& Zucker's book.

\section{Acknowledgements:}

I would like to thank Rachel Cooper, George Turner, Faye Tucker, Hane Maung, Annika Dahlin, Dan Degerman and Tomasz Herok who read and offered helpful criticism of earlier versions of this article. My research is funded by a scholarship from the Economic and Social Research Council, ESRC Ref: $\mathrm{ES} / \mathrm{I} 02767 \mathrm{X} / 1$.

\section{Bibliography:}

Asperger, Hans. (1991). 'Autistic psychopathy' in childhood. 37-93. in Frith, Uta (ed). Autism and Asperger Syndrome Cambridge: Cambridge University Press).

Chown, Nick. (2012). 'History and First Descriptions' of Autism: A response to Michael Fitzgerald, Journal of Autism and Developmental Disorders, 42/10, 2263-2265.

Cooper, Rachel. (2007). Psychiatry and the Philosophy of Science (Stocksfield: Acumen).

Cushing, Simon. (2013). Autism: The Very Idea. 17-47. in Anderson, Jami, L. \& Cushing, Simon. (eds). The Philosophy of Autism (Plymouth: Rowman \& Littlefield).

Darr, George C. \& Worden, Frederic G. (1951). Case Report Twenty Eight Years After an Infantile Autistic Disorder, American Journal of Orthopsychiatry, 21/3, 559-570.

Evans, Bonnie. (2013). How autism became autism - The radical transformation of a central concept of child development in Britain, History of the Human Sciences, 26/3, 3-31.

Eyal, Gil., Hart, Brendan., Onculer, Emine., Oren, Neta., \& Rossi, Natasha. (2010). The Autism Matrix. Cambridge: Polity Press.

Feinstein, Adam. (2010). A History of Autism: Conversations with the Pioneers (Chichester:

WileyBlackwell).

Fellowes, Sam. (2015). Did Kanner actually write the first account of Autism? The mystery of 1938, Journal of Autism and Developmental Disorders. 45/7, 2274-2276.

Lyons, V., \& Fitzgerald, M. (2007). Asperger (1906-1980) and Kanner (1894-1981), the two pioneers of autism, Journal of Autism and Developmental Disorders, 37/10, 2022-2023.

Kanner, Leo. (1943). Autistic Disturbance of Affective Contact, Nervous Child, 2, 217-250. 
Kanner, Leo. (1958). The specificity of Early Infantile Autism, Acta Paedopsychiatric, 25/1-2, p.108113.

Kanner, Leo. (1953). Childhood Schizophrenia Round Table, American Journal of Orthopsychiatry, 24/3, 526-528.

Kanner, Leo., \& Eisenberg, Leon. (1955). Notes on Follow-up Studies of Autistic Children in Hock, Paul, H., \& Zubin, Joseph (Eds.), Psychopathology of Childhood. New York: Grune and Stratton. Kanner, Leo. (1969). The Children Haven't Read Those Books, reflection on differential diagnosis, Acta Paedopsychiatrica, 36, 2-11.

Kanner, Leo. (1971). Follow-Up Study of Eleven Autistic Children Originally Reported in 1943, Journal of Autism and Childhood Schizophrenia, 1/2, 119-145.

Kanner, Leo. (1973). How Far Can Autistic Children Go in Matters of Social Adaption. 189-214. in Kanner, Leo. (ed.). Child Psychiatry: Initial Studies and New Insights (New York: Winston \& Sons).

Kanner, Leo. \& Lesser, Leonard, I. (1958). Early Infantile Autism, Pediatric Clinic North America, 5/3, 711-730.

Jacobsen, Kurts. (2010). Diagnostic Politics: the curious case of Kanner's syndrome, History of Psychiatry, 21/4, 436-454.

Murphy, Dominic. (2006). Psychiatry in the Scientific Image (Massachusetts: Massachusetts Institute of Technology).

Nadesan, Majia, Holmer. (2005). Constructing Autism (London: Routledge).

Olmsted, Dan., Blaxill, Dan. (2016). Leo Kanner's Mention of 1938 in His Report on Autism Refers to

His First Patient, Journal of Autism and Developmental Disorders, 46/1, 340-341.

Silverman, Chloe. (2012). Understanding Autism: Parents, Doctors, and the History of a Disorder.

New Jersey: Princeton University Press.

Timini, Sami., Gardner, Niel. \& McCabe, Bain. (2011). The Myth of Autism (Palgrave-McMillian). Verhoeff, Berend. (2013). Autism in flux: a history of the concept from Leo Kanner to DSM-5, History of Psychiatry, 24, 442-458.

Zachar, Peter. (2014). A metaphysics of Psychopathology (Massachusetts: Massachusestts Institute of Technology Press). 